\title{
Conflictos territoriales y culturales en la renovación del frente costero, Rosario (Argentina)
}

Diego Roldán. Consejo Nacional de Investigaciones Científicas y Tecnológicas (Conicet), Rosario, Argentina.

Sebastián Godoy. Consejo Nacional de Investigaciones Científicas y Tecnológicas (Conicet), Rosario, Argentina.

RESUMEN | Este trabajo reconstruye el proceso de ocupación, desalojo y desposesión de dos experiencias de producción de espacio urbano en una ciudad del Sur Global: Rosario (Argentina). Nos centramos en la franja urbana de la costa central, escenario de las trayectorias de dos sujetos colectivos, los okupas y los pescadores artesanales. Ambas comunidades presentaron formas alternativas de producir e imaginar el espacio urbano y plantearon la necesidad de generar diferencias con las tendencias corporativas que mercantilizaban la ciudad, su cultura y sus modos de vida. A través de sus prácticas y resistencias cotidianas, okupas y pescadores mostraron alternativas espaciales y futuros culturales-productivos para una genealogía y cartografía del presente urbano. Mediante una combinación de la hermenéutica etnográfica e historiográfica, intentamos mostrar las prácticas de resistencia a las fórmulas gubernamentales de la renovación urbana.

Palabras ClaVe | espacio público, transformaciones, socioterritorial, urbanismo.

ABSTRACT | This work studies the process of occupation, eviction, dispossession and concealment of two experiences of urban space production in a Global South city: Rosario (Argentina). We focus on the Parana waterfront, the landscape of two collective subjects: the okupas (squatters from Rosario) and the artisanal fishermen. Both communities presented alternative ways of producing and imagining urban space and identified the need to generate differences from the corporate tendencies that commodified the city, its culture and its ways of life. They also collectively came up with new forms of producing, learning and sharing knowledge, in order to strengthen their self-organized communities. Through their practices and everyday resistances, they showed alternative possible paths and futures in a genealogy and cartography of the urban present. Through a combination of ethnographic and historiographical hermeneutics, we studied the practices of resistance to the governmental formulas of urban renewal.

KEYWORDS | public space, social-territorial transformations, urbanism.

Recibido el 21 de julio de 2018, aprobado el 3 de junio de 2019.

E-mails: D. Roldán, diegrol@hotmail.com | S. Godoy, sebasgodoy13@gmail.com 


\section{Introducción}

Las ciudades han ganado un marcado protagonismo a partir de la crisis económica de 1973, el paulatino declive de las funciones del Estado Nacional y la aplicación de políticas económicas relativamente ensambladas con el neoliberalismo. En el contexto latinoamericano de los ańos 1990, este proceso fue acompańado por las reformas de tercera generación de los Estados Nacionales, el desembarco de los esquemas neoliberales de gestión pública y la tercerización de la economía. En Argentina se iniciaron procesos de privatización de las empresas del Estado, en los que intervinieron capitales europeos tanto públicos como privados. Asimismo, la descentralización y privatización comportaron la transferencia no solo de funciones y atribuciones del Estado Nacional a los Estados Provinciales y los municipios, sino también de bienes e infraestructuras, como los puertos y ferrocarriles (Portes, Roberts, \& Grimson, 2005). Las administraciones locales acusaron el impacto de los nuevos flujos económicos globales, que ubicaban a los desarrollos urbanos en un primer plano para colocar los excedentes y las rentas extraordinarias del capital (Harvey, 2005). La convergencia, no siempre armoniosa, de inversiones privadas y planificación pública puso en marcha el reciclaje y la patrimonialización de infraestructuras obsoletas. Estos procesos generaron productos diferenciales, dependiendo del ensamblaje de los flujos globales de ideas, capitales y diseńos con las condiciones locales de la geografía, las huellas patrimoniales, las tradiciones urbanísticas, etcétera.

Rosario, la segunda ciudad portuaria de la Argentina, sufrió una serie de transformaciones a partir del último cuarto del siglo xx. La recualificación de las instalaciones ferroportuarias de la ribera del Paraná constituyó el eje prioritario de esa modificación. Sin embargo, la necesidad de reestructurar la relación de la ciudad con la costa a través de una secuencia de parques fue un proyecto que se desenvolvió a lo largo del siglo xx. Al promediar los años 1920, las fuerzas vivas de la ciudad, algunos funcionarios y un grupo de urbanistas buscaron relocalizar los ferrocarriles y el puerto, entendiendo a estas infraestructuras como barreras, cinturones y trabas que limitaban la interconexión de las distintas partes de la ciudad (norte y sur) y la relación de la ciudad con el río. Desde el Plan Regulador de 1935 se propuso la relocalización parcial del puerto y la construcción de un sistema de espacios verdes sobre parte de la franja costera. Este diagnóstico fue profundizado en el Plan de 1952, y el desplazamiento del puerto hacia el sur de la ciudad fue planteado claramente por el Plan de 1968. Las concesiones a empresas extranjeras del puerto (hasta 1942) y de los ferrocarriles (hasta 1948) impidieron la concreción de las previsiones del Plan Regulador de 1935; y el golpe de Estado de 1955, aquellas inscriptas en el plan de 1952. Durante la dictadura de Juan Carlos Onganía, se sancionó el Plan de 1968. Sus orientaciones fueron aplicadas de manera discrecional por la última dictadura militar de 1976. Especialmente, estos incumplimientos se verificaron en la zona de Puerto Norte, área de recuperación prioritaria de la ribera, donde firmas privadas continuaron desarrollando actividades portuarias y se comprometieron nuevas concesiones. Desde comienzos de los años noventa, la costa de Rosario fue objeto de un sostenido proceso de reconfiguración y transformación pública, cuyo 
punto inicial fue el Plan Director de 1991, que actualizaba, complejizaba y flexibilizaba los supuestos del Plan Regulador de 1968. Estas tentativas de recualificación y construcción de un waterfront coincidieron con la instalación perdurable de un gobierno local vinculado al Partido Socialista, la obsolescencia de las instalaciones portuarias respecto a las nuevas dimensiones de los transportes marítimos, la creación de la región contractual de Mercosur (1991), los acuerdos para el trazado de la hidrovía Paraná-Paraguay (1992) y posterior adjudicación de su licitación (1995), la inauguración del puente Rosario-Victoria (2003), un contexto latinoamericano de reforzamiento de las gestiones locales, y la construcción de enlaces con modulaciones europeas de un urbanismo arquitectónico y patrimonialista. A partir de esas convergencias, se operó la conversión de una Rosario tradicionalmente ferroportuaria $y$, desde mediados del siglo xx, circundada por un cordón industrial, en una ciudad de servicios. Con la inauguración del Centro Cultural Parque de España (СCPE) en 1992, la costa central y norte de la ciudad se convirtieron en los espacios destinados a ser renovados y valorizados. El CCPE es una pieza arquitectónica proyectada entre 1979 y 1981 por el estudio Martorell-Bohigas-Mackay (Jajamovich, 2012), cuya construcción observó numerosas dilaciones por ausencia de financiamiento (Robles, 2015). La antigua infraestructura ferroportuaria fue intervenida con nuevos módulos arquitectónicos polifuncionales. Esta serie de operaciones se han prolongado en el tiempo y el espacio. Sus resultados han variado y pueden dividirse en distintas etapas. Entre 1992 y 2003, entre la inauguración del Parque de España y el Puente Rosario Victoria, se promovió la construcción de espacios públicos, centros culturales, el mantenimiento de las concesiones de los clubes de pesca y algunos emprendimientos gastronómicos. Desde 2005 a la actualidad, entre el Museo de Arte Contemporáneo Rosario (MACro) y Ciudad Ribera, a esa línea se ha incorporado el desarrollo medular de los emprendimientos gastronómicos y las fórmulas habitacionales de alta gama, y se evidencia una menor presencia de instituciones culturales públicas.

Gran parte de la valoración política y académica de estas intervenciones, especialmente de la primera etapa, ha sido muy positiva (Cuenya, 2012; Levin, 2012; Madoery \& Caminotti, 2000). Los argumentos han subrayado que la mayoría de los terrenos estaba en manos privadas y que los procesos de recualificación y construcción del waterfront no solo reemplazaron la relación ciudad-puerto por una relación ciudad-espacio público, sino que abrieron para el disfrute de la ciudadanía numerosas hectáreas. Respecto a los procesos más actuales, se ha destacado el estudio de la ingeniería institucional del Municipio para recuperar las plusvalías generadas por los cambios en los usos del suelo y el ordenamiento territorial. Sin embargo, el proceso que abrió Puerto Norte no ha podido ocular cierta fragmentación y construcción de desigualdades. Debido a ello, en los últimos años se han generado algunas narrativas críticas (Baremboim \& Tomino, 2016; Galimberti, 2016; Scarpacci, 2014; Vera, 2017). No obstante, estos trabajos se concentran en analizar diversas facetas de la renovación urbana en el plano infraestructural, el proyectual, la construcción simbólica y la producción política, aunque la atención que prestan a los sujetos afectados por esos procesos es más bien tangencial. 
De una miscelánea de fuerzas, intereses y usos, orientados por la convergencia de la planificación estratégica, el diseño público y la inversión privada, emergió un waterfront en proceso de consolidación. La nueva línea costera se caracterizó por intervenciones temporalmente discontinuas, mientras que espacial y morfológicamente sus resultados han sido desiguales. Esos territorios son suturados por una línea de espacios públicos conectados por avenidas. En este artículo, estudiamos algunos de los hilos todavía visibles de esa costura urbana. Sus nudos conflictivos fueron atados por la lógica doble de la recomposición y la borradura que afectó y afecta a dos tipos de residuos del área. El primero es material-arquitectónico: las instalaciones remanentes de la antigua interfaz ferroportuaria de la ciudad, objeto de reciclaje y patrimonialización. El segundo residuo es de tipo relacional-subjetivo: los sujetos, las existencias comunitarias y las prácticas culturales que habitaron esas infraestructuras y sus inmediaciones.

Dos comunidades, los okupas y los pescadores artesanales, son conceptualizados como segmentos de las multiplicidades que la gubernamentalidad local ha intentado desalojar del espacio de recualificación. En general, estos sujetos sociales no han sido considerados por los abordajes de los procesos de transformación urbana, que han privilegiado comunidades más estables, mejor enraizadas en la vida urbana y con organizaciones más visibles y dispuestas a la negociación (Janoschka, 2016). Nuestra intención es analizar cómo okupas y pescadores, a partir de prácticas antes que de programas políticos, pusieron en cuestión las intervenciones urbanísticas y la planificación estratégica que guía la renovación de la costa central.

Promediando los años 1990, los okupas conformaron un conjunto cultural de procedencia difusa y transformaron un antiguo galpón ferroviario en un centro cultural independiente. Algunas de las artes performáticas que desarrollaron abarcaron desde el circo hasta los recitales de rock alternativo. Al menos veinte años antes, un grupo de pescadores se afincó en la barranca y desplegó su producción artesanal. Sus formas de vida, sus modos de producción y su relación con el ambiente contrastan con las fórmulas del extractivismo ictícola de los grandes frigoríficos y acopiadores de sábalo. Los pescadores hicieron de la barranca su hábitat y territorio de (re)producción social, económica y cultural. Ambos grupos fueron desalojados de esos espacios por distintas fuerzas gubernamentales. En 1998, cuarenta efectivos de Gendarmería Nacional expulsaron a los okupas del galpón, y en 2007 un considerable número de pescadores perdió sus viviendas a manos de unos pocos efectivos de Defensa Civil, los Bomberos y la Policía Provincial. Si bien estos dos acontecimientos están separados por una década, se encuentran enlazados por la conflictividad inscripta en las lógicas alternativas de ocupación, codificación y uso del espacio costero de okupas y pescadores y el despliegue de los dispositivos del espacio público.

A continuación, abordaremos las prácticas culturales que promovieron estos grupos. Reflexionaremos en torno a las condiciones en las cuales fueron objeto de desalojo. Además de ese destino común, indagaremos en las relaciones posibles de ambos colectivos. A partir de ese ensamblaje de coincidencias diferenciadas, ensayaremos establecer un contrapunto con la lógica de patrimonialización y puesta en valor selectiva que, en nuestro caso, atiende sobre todo a la materialidad edilicia, 
al mercado inmobiliario, la actividad gastronómica, los bienes culturales comodificables, y desestima las existencias sociales y culturales con menor capacidad de mercantilización. Cada uno de nosotros visitó una de las comunidades y desarrolló observaciones participantes y/o entrevistas en profundidad. En el caso de los okupas, solo pudimos recurrir a las entrevistas y a la memoria de los miembros del grupo original, quienes hoy en día se encuentran relativamente distanciados de aquella experiencia. Los pescadores presentan una condición intermedia. Si bien su afincamiento en la costa central ha declinado, cuando realizamos las entrevistas nuestros informantes principales (Ramón y Carlos) residían en el área y pudo recurrirse tanto a las entrevistas como al trabajo de campo con observación participante. Esto plantea una situación híbrida. Por un lado, hay una evocación a la comunidad y la resistencia como hechos pertenecientes al pasado. Por otro, las ruinas de esa experiencia continúan activas, pueden recuperarse e interpelan a la porción minoritaria de pescadores artesanales que permanece en la ribera central y continúa desarrollando su oficio. La metodología de aproximación a este problema combina el trabajo etnográfico con la comunidad de pescadores, la hermenéutica historiográfica de los documentos oficiales y periodísticos y algunas técnicas de la historia oral aplicadas, especialmente, al antiguo colectivo de los okupas.

\section{El Galpón Okupa: usos y culturas alternativas en la ciudad posferroportuaria}

El espacio público fue el escenario de las prácticas al aire libre que promovieron la reunión de jóvenes rosarinos. Hacia 1996, varios grupos frecuentaron la zona comprendida por los parques de España y de las Colectividades. Buscaban esparcimiento, un lugar para encontrarse y compartir. Los cultores de las "artes urbanas" hallaron el sitio para ensayar, perfeccionarse y socializar saberes. También hubo quienes observaron esas prácticas e intercambiaron información sobre eventos. La multiplicidad de orígenes y la diversidad de intenciones ampliaron el circuito de la interacción. De las actividades, la más concurrida y espectacular era la Fiesta del Fuego. Los participantes se congregaban los domingos hacia el atardecer, formaban un círculo, bailaban, cantaban, hacían malabares y prácticas expresivas. Tras la caída del sol, entregaban objetos al fuego: clavas incendiadas y kerosene soplado sobre antorchas. El sonido de los tambores y la luminosidad de los palos indicaban el sitio de la Fiesta. Ese espacio era "un lugar sin reglas, de nadie y, por eso mismo, de todos" (Pablo, entrevista personal, 26/03/2014). El público era ocasional y espontáneo. Las reuniones, horizontales y autónomas. Sostenido por la subjetividad nómada de sus participantes, ese espacio eventual parecía quebrar la materialidad y la continuidad temporal de la ciudad. Como heterotopía (Foucault, 2010), la Fiesta del Fuego constituía una desgarradura en el tejido espacial homogéneo y en la secuencia temporal rutinaria de la ciudad.

Los objetos -tambores, clavas, zancos- eran traídos por los participantes, quienes al finalizar la actividad regresaban con ellos. Algunos comenzaron a explorar la posibilidad de generar un espacio más resguardado y estable. A mediados de los 1990, los aficionados al punk rock deambulaban por plazas y parques, intercambiaban información de recitales, casetes piratas, fanzines y, también, buscaban un lugar. 
Ambos grupos se interesaron en un antiguo galpón ferroviario. Al norte del Parque de España, el galpón permitía organizar la Fiesta del Fuego y ofrecer algunos recitales. La estructura colmaba las expectativas del heterogéneo ensamble cultural. En 1997, el edificio fue intervenido y convertido en El Okupa.

Al galpón lo teníamos marcado hacía tiempo, [...] estaba buenísmo, todo abandonado. Un día, ocupamos finalmente el galpón. Lo empezamos a limpiar y algunos se quedaron a vivir. (Xaxi, entrevista personal, 28/05/2015)

Unos diez jóvenes ingresaron al inmueble. Los primeros habitantes se instalaron en tres horas. En el periodo de mayor actividad, el edificio integró espacios comunes y específicos. Había una sala de danza y pintura, en el otro cuerpo del edificio funcionaban "el Bar, el Cielo [un entrepiso donde había una sala de ensayo], el Aire [un segundo entrepiso]. Y abajo del Cielo, claro está, arde el Infierno" (Rolling Stone, no 5, agosto de 1998, p. 73). Algunas áreas eran de uso común y otras estaban "okupadas". Una diversidad de formas de intervención, uso y habitación persistió por casi dos años. Había un núcleo de habitantes semipermanentes, con renovación periódica, formados por los carentes de hogar y los que deseaban abandonarlo. Sin embargo, no todos los que utilizaban las instalaciones vivían allí.

La situación del Galpón Okupa era algo diferente a las experiencias de los squatters y okupas europeos (Martínez López, 2012). Gran parte de los okupas rosarinos actuaban "instintivamente y sin conocer lo que ocurría en otros lugares" (Pablo). Entre ellos no había objetivos fijos ni una visión clara del futuro. La actividad consistía en pasar el tiempo, disfrutar del ocio y compartir bebidas, cigarrillos y panificación del día anterior. Todo lo que pudiera consumirse colectivamente, pasando de mano en mano, era bienvenido. Pronto recibieron amenazas policiales, que abarcaban desde advertencias de uniformados hasta intimidaciones nocturnas. Luego de unos meses, surgió una iniciativa más reflexiva sobre el propósito del Galpón Okupa. Se ensayó conformar un Centro Kultural Independiente que ofreciera talleres abiertos, gratuitos o "a la gorra". De orientaciones variadas, decenas de talleristas desfilaron por el Galpón. Los espacios de aprendizaje de las artes circenses fueron muy concurridos. A esas propuestas se ańadieron talleres de guitarra, tango, artesanías, pintura, ajedrez y teatro.

En el Okupa, los movimientos sociales, las agrupaciones políticas y los organismos de derechos humanos realizaron asambleas y ciclos de charlas. Cuando se conocieron las primeras noticias de apremios policiales, la Red de Solidaridad con Chiapas se vinculó al lugar. Sus miembros, no obstante, ignoraban lo que era una "okupación urbana” (Pablo y Amalia, entrevista personal conjunta, 4/04/2015). Una vez que conocieron a los okupas y sus actividades, comenzaron a asistir al taller de artesanías y realizar asambleas -al modo zapatista- con el objetivo de resistir a posibles desalojos. Asimismo, el Galpón aparecía como un espacio propicio para las experiencias libertarias. Miembros de la biblioteca anarquista Alberto Ghiraldo, difundieron el material documental de la okupación madrileña de la imprenta Minuesa (Adell \& Martínez, 2004), una experiencia organizada alrededor de la reivindicación del derecho a la vivienda. Desde la biblioteca se buscó atribuirle contenido político a la okupación rosarina. Más jóvenes que los anarquistas y escépticos frente al zapatismo, 
los okupas se opusieron. Afirmaban haber roto con las normas de la sociedad capitalista y no necesitar regulaciones. La experiencia del Galpón se ponía en acto a través de la práctica cultural cotidiana. Sus objetivos a corto plazo eran "resistir al orden hegemónico" (Pablo) y no someterse a ningún mandato. Esta actitud radical dificultó el ingreso de cualquier ideología organizativa.

En su apogeo, el Okupa funcionaba de manera continua. Los primeros días de la semana se dictaban los talleres y organizaban las reuniones. Los jueves había teatro y ciclos de cine. Los viernes y sábados estaban dedicados a los recitales. Finalmente, los domingos se destinaban a la limpieza y la comida comunitaria. A mediados de 1998, los recitales hicieron conocido el Galpón entre los jóvenes. Se sucedieron alrededor de setenta y cinco conciertos, a los que asistieron cientos de bandas de punk, metal, música circense y variaciones del rock. Si bien el sonido era costoso y siempre "existía el peligro de que te caiga algo encima", los organizadores recuerdan el Galpón como un espacio interesante de la escena experimental y under local (Zalo, entrevista personal, 20/05/2015). En su segundo año de vida, el Centro Kultural había reacomodado sus instalaciones para albergar a unas trescientas personas por recital. Entonces, el inmueble contaba con "un escenario de tres pisos, cosa nunca vista en Rosario" (Xaxi). Bandas nacionales, invitadas de México y Espańa, desfilaron por el antiguo local ferroviario. Las formaciones musicales alternativas siempre disfrutaron del hecho de tocar en un lugar "clandestino".

Múltiples géneros artísticos se encontraron productivamente en el Galpón: malabares y punk rock, payasos y artesanos, artes visuales y juegos de mesa. El espacio permitió la circulación, hibridación y experimentación. En esos encuentros, las disciplinas perdieron sus formas "puras" y sus repertorios de origen.

Esa fusión hizo que salieran algunos espectáculos de calle cada vez más constituidos. Se creó una movida en la que la gente venía y sabía que siempre encontraba algo en los parques los fines de semana. Sábados y domingos presentábamos, lo que era una salida laboral, y durante la semana entrenábamos. (Tati, entrevista personal, 18/12/2014)

Para muchos, el Okupa significaba una nueva forma de vida. Les otorgaba una libertad que, sin embargo, debía apuntalarse con trabajo. En un lugar horizontal y marginal, las tareas de mantenimiento implicaban un repertorio de organización que había que sostener colectiva y corporalmente. Pedir comida en bares y panaderías, higienizarse poco y convivir con una corriente de personas e intenciones heterogéneas eran parte del aprendizaje colectivo. En un espacio sin reglas y con sujetos diversos, no tardaron en aparecer conflictos alrededor de la dinámica del ocio.

Este lugar te agota $[\ldots]$ hay que convivir con diecinueve personas distintas, que no piensan lo mismo que vos, que como vos son egoístas. Uno trata de buscar la paja en el ojo ajeno [...]. El problema es cuando hay gente que okupa pero no se ocupa [...]. El ocio los consume. (Rolling Stone, $\mathrm{n}^{\circ}$ 5, agosto 1998, p. 73).

Mientras muchos trabajaban para mejorar el espacio, otros simplemente pasaban sus días ensuciando y consumiendo, no aportaban al trabajo común. De todos modos, era imposible obligar a nadie. El Galpón no contaba con reglas, una situación que 
ocasionó animosidades entre algunos okupas. En el segundo año de ocupación, el Galpón recibió nuevos miembros que habían presenciado la experiencia squatter europea. Entonces, se abrió un ciclo de confrontaciones internas.

Hubo muchas discusiones, acerca de qué significaba una okupación y si una okupación en Latinoamérica tenía que ser una okupación ideológica y contracultural como Europa o si acá era una cuestión de necesidad por las condiciones de vivienda y de un carácter más ligado a lo artístico. (Pablo)

La falta de un proyecto explícito subrayó las diferencias pragmáticas sobre qué hacer y cómo vivir en el Galpón. Por el torrente de esos debates, se escurrieron "personas valiosísimas". Muchos no comprendían la naturaleza de la okupación: "...no bastaba con okupar, había que ganar el espacio" (Xaxi). Así, se debilitó la masa crítica que hubiera contribuido al fortalecimiento de la resistencia ante las presiones externas. La palabra "Resiste" estaba estampada sobre la piel de varios de los habitantes y en algunas de las paredes del Okupa.

Por más de un año y medio, la Provincia y la Municipalidad intentaron desalojar el Galpón. La estructura pertenecía a un Ente Administrador Nacional de Bienes Ferroviarios (Enabief) de jurisdicción nacional. El 29 de junio de 1998, un juez nacional firmó una orden de desalojo. Una abogada vinculada a la Asamblea Permanente por los Derechos Humanos (APDH) solicitó una prórroga. Para los okupas, el gobierno local se había "lavado las manos", actuando como si fuera propietario del inmueble.

[...] durante un año y pico estuvimos negociando de buena fe con funcionarios de segunda línea creyendo que el dueño de los galpones era el municipio. No sabíamos nada de esto del Enabief hasta que un día llegó una delegación del juzgado federal $[\ldots]$ mientras tanto, nos hicieron pasar por decenas de oficinas. (Página 12, $12 / 12 / 1998)$

A mediados de 1998, la noticia del suicidio de María Soledad Rosas, una joven argentina que vivía en un edificio de Turín ocupado por squatters, sacudió a los medios nacionales. Años después, el escritor Martín Caparrós (2006) le dedicó un trabajo a medio camino entre la investigación periodística y la ficción. Buscando ampliar la biografía de la joven, la prensa nacional fue tras sus "primos argentinos" (Clarín, 30/08/1998). En esa pesquisa, apareció la historia de los okupas rosarinos. Por entonces, los únicos similares a los europeos. Una lluvia de reporteros cayó sobre Rosario. Frente al interés mediático, los okupas intentaron visibilizar las actividades culturales del Galpón. No hablaron de déficits habitacionales ni demandas sociales: prefirieron tomar la cultura y el arte, la creación colectiva, abierta y gratuita como estandartes. Imágenes del Okupa y sus habitantes fueron replicadas en diarios, revistas y pantallas de televisión. Activos y movilizados, los okupas realizaron radios abiertas, ollas populares, volanteadas y recitales que inundaron la ciudad. Ese fue su último acto de resistencia. Con el declive de la inquietud por el caso Rosas, los okupas fueron desapareciendo de los medios.

A mediados de 1998, fuerzas de la Policía de Santa Fe y Gendarmería Nacional desalojaron el Galpón. Rápido y contundente, el operativo estaba amparado en 
una orden judicial. Los okupas evitaron enfrentarse con los uniformados. Así describieron el operativo que los expulsó del lugar: "No hubo violencia física, pero nos presionaron por la forma en que vinieron armados y equipados" (La Capital, 13/08/1998). A modo de réquiem para su causa y sus espacios de experimentación artística, cultural y existencial hicieron un acampe. Finalmente, se dispersaron.

En pocas semanas, el Municipio se hizo cargo del inmueble. El primer Plan Estratégico (PER), presentado en esos meses e inspirado en los diseños catalanes (Borja \& Castells, 1997), reafirmaba el reciclaje recreativo y cultural de las instalaciones ferroportuarias. El PER apuntaba a consolidar Rosario como "polo de atracción cultural" (El Ciudadano, 30/10/1998). Asimismo, instaba a impulsar "la industria cultural" mediante "iniciativas públicas y privadas" (Plan Estratégico Rosario 1998, p. 256, en adelante PER). El Centro Cultural Parque Espańa (CCPE), inaugurado en 1992, había señalado el camino: producir espacios singulares y distribuirlos a lo largo de la costa central a modo de usinas de arte abiertas al público, y la gestión internacional con potencial y aún incipiente participación empresarial.

Al calor de estas ideas, el Galpón fue entregado a la Academia del Tango. Todavía no se habían relevado las condiciones del edificio ni conseguido los patrocinadores para remodelarlo (El Ciudadano, 9/10/1998). De forma improvisada, en octubre de 1998, los impulsores del proyecto inauguraron la "Casa del Tango" (figura 1). La falta de inversiones privadas y la insolvencia del sector público aplazaron seis años su apertura definitiva. Con propuestas musicales y audiovisuales, la Casa del Tango replicó parcialmente el espíritu del CCPE, añadiendo emprendimientos gastronómicos.

Esta historia de desposesión estuvo marcada por cierta incomprensión. Los funcionarios locales no pudieron decodificar qué ocurría en el Galpón. No entendieron la relación cultural creada por sus habitantes con el espacio. Su primera reacción fue tratarlos como indigentes o personas sin hogar.

$[\ldots]$ vinieron una trabajadora social y tres funcionarios municipales. Llegaron a negociar como negociarían con una familia de la villa (nos querían dar algunas chapas y colchones para que nos vayamos) y encontraron a un montón de personajes que venían de diferentes formaciones, algunos instruidos, una heterogeneidad, gente que se les plantó y les empezó a tirar argumentos que los descolocaron absolutamente. Los tipos quedaron totalmente en offside y el director de Control Urbano se enojó y se fue a las puteadas, sin terminar de definir la mediación. (Pablo y Amalia)

Los okupas formaban parte y rompían con el tejido cultural urbano. Habitaban en las ruinas reciclables de la ciudad ferroportuaria y se alimentaban de despojos, pero producían novedades. Esos productos culturales no se asimilaban a la forma mercancía y no podían venderse en los circuitos comerciales existentes. Los okupas debatían la horizontalidad entre lo individual y lo colectivo. Eran indescifrables para los ojos de la gubernamentalidad. Eran y no eran una comunidad, eran y no eran hijos de una posmodernidad periférica, emplazados en las zonas liminares del espacio urbano, donde la ciudad se encuentra con el río; también habitaban un pliegue del tiempo a medio camino entre la globalización y la historia local. Esa 
posición ambigua hizo de los okupas un punto de ilegibilidad en el flujo urbano de los años 1990.

El Municipio había integrado a su organigrama cultural a otras experiencias autónomas de manera más eficaz. Al sur del Galpón, se encontraba la Escuela Municipal de Artes Urbanas (EMAU). Algunos artistas circenses, vinculados al Okupa, fueron integrados a esas propuestas culturales oficiales. No obstante, el Galpón como espacio-experiencia y sus actividades no fueron incluidas en los planes de revitalización cultural y urbana sostenidos por el PER 1998. Significativamente, la Municipalidad asimiló varios de sus lenguajes artísticos, pero prefirió sustituir el espacio que los había hecho posibles con la "Casa del Tango". Quizás esta decisión obedeciera a que esas prácticas habían surgido a partir de una lógica poco mercantilizable que contrastaba con las nuevas Ciudades Creativas (Peck, 2015). La autoorganización, la horizontalidad, la resistencia a los ritmos urbanos y la circulación no monetarizada de saberes y objetos no eran codificables para la nueva gubernamentalidad. Las formaciones culturales okupas se incubaron en la potencia de los encuentros fortuitos forjados en las calles, los parques y las plazas. Un grupo de sujetos inventaron en el Galpón un espacio alternativo, capaz de florecer al margen de las industrias, las planificaciones y las estrategias culturales.

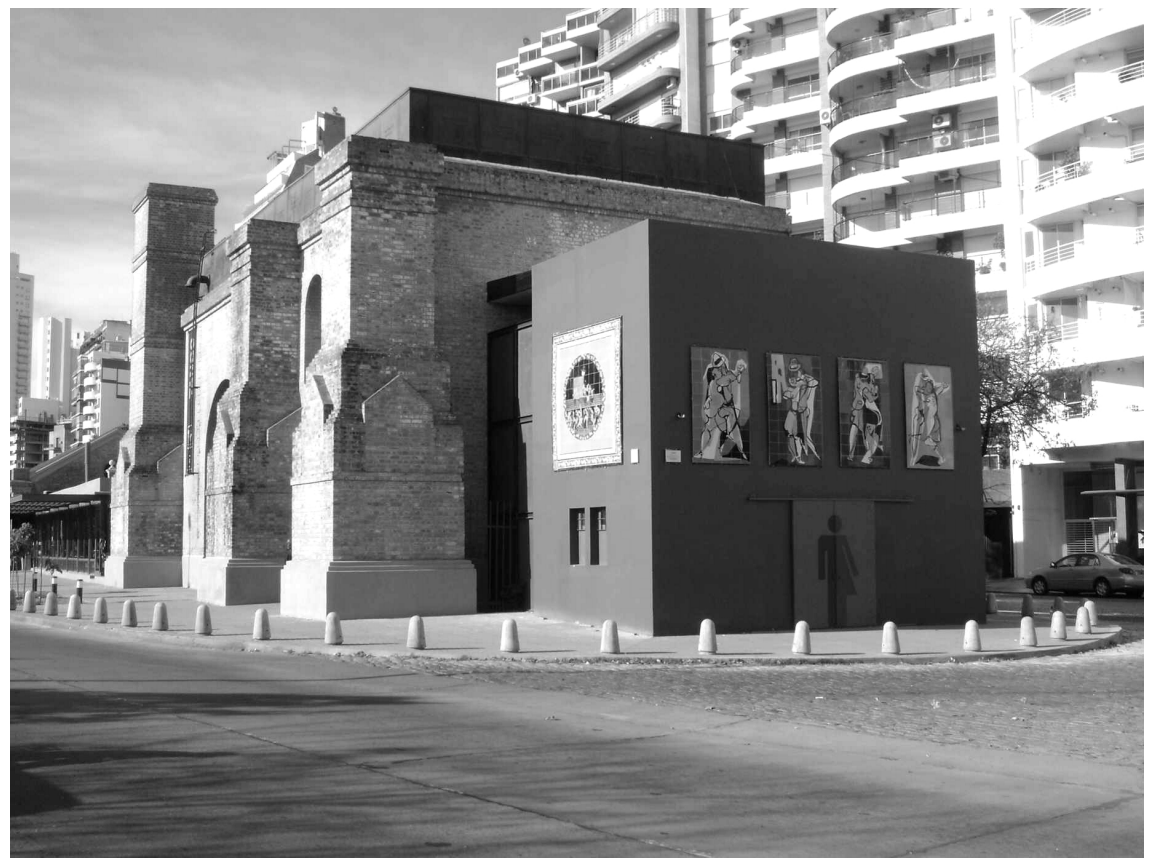

Figura I | La casa del Tango. Antiguo Galpón Okupa

FUENTE: PLAN URBANO ROSARIO 2007 


\section{Los pescadores y los espacios públicos de la costa central}

El pescador tiende a hablar del río como de una parte de su vida, casi como de una prolongación de su cuerpo. La costa, donde amarra la canoa, guarda los aparejos y las redes, es su territorio. Allí vive, cuando no está en la canoa, sobre el agua. La identidad de los pescadores se define antes por la profesión, el conocimiento del oficio, unas formas culturales y un modo de vida que por la convivencia prolongada o los lazos sociales. El pescador es un hombre-que-vive-del-río y un artesano. Los pescadores experimentados tejen y confeccionan sus propias redes, arreglan y calafatean sus embarcaciones. Saben en qué periodo del año y en qué lugar del río pueden encontrar mayor cantidad y variedad de peces, conocen el tamaño promedio de las especies, incluso llegan a hacer estimaciones acerca de su tasa de reproducción y crecimiento. Escudriñan el movimiento de los cardúmenes, establecen patrones y relaciones entre los desplazamientos y el clima, la amplitud térmica, el régimen de lluvia y las crecidas (Castillo, Baigún, \& Minotti, 2016). Los pescadores artesanales protegen el origen de sus conocimientos. El proceso de transmisión cultural es largo, tortuoso y está articulado alrededor de un sentido práctico y un uso de tecnologías específicas.

Los pescadores reivindican su estilo de vida, alejado de las convenciones urbanas. Hablan de una existencia ligada a la naturaleza, establecen una relación de implicación simbiótica con el río. Ramón, nuestro informante clave, señala que prefiere que el río lo golpee con una mala jornada de pesca, a que un patrón le baje el salario. Dice respetar más las relaciones que establecen los hombres con el río y sus técnicas de pesca que las que podría entablar con un entorno laboral urbano. Debido a este carácter artesanal que fomenta cierto individualismo, diferencia y dispersión, las asociaciones y sindicatos de pescadores son un fenómeno tardío. Aparecieron junto a los nuevos actores corporativos que amenazan con apropiarse del río y sus recursos: los grandes acopiadores y los frigoríficos de pescado. Un antagonista menos explícito se inscribe en el desarrollo de infraestructuras ambientalmente invasivas (Puente Rosario Victoria y el dragado para la Hidrovía). También existe una disputa con las prácticas vinculadas a los usos recreativos del río, tales como la pesca deportiva, la expansión de los deportes acuáticos y la proliferación de embarcaciones y guarderías.

En las pequeñas comunidades pesqueras, estas transformaciones tuvieron un impacto negativo: la reducción del espacio de maniobra dentro y en las orillas del río. Esta concatenación de eventos, que acorralan la actividad y amenazan con desplazar definitivamente a los pescadores artesanales de la costa, impulsó un proceso acelerado e inestable de producción de una identidad colectiva. Se trata de una identidad expresada en términos de antagonismo social y a través de mecanismos narrativo-políticos. En esa construcción, la desposesión del territorio y la resistencia por sostener su modo de vida conforman una dupla de fuerzas cardinales.

Los pescadores produjeron un relato oral del desarrollo histórico de esa identidad y de las prácticas culturales-artesanales, cuyo escenario principal es la ribera. El 
pulso de esa historia está marcado por una ocupación remota y por episodios de desposesión recientes. La narrativa se remonta al siglo XIX, a un periodo anterior al desarrollo del puerto de Rosario, cuyas posibles verificaciones empíricas son tan difíciles como improbables. Los pescadores desean afirmar que su ocupación de la ribera es casi tan antigua como la existencia de la ciudad. Esa especie de larga duración les permite disputar sentido y territorio con el agrupamiento urbano que ha crecido detrás de la ribera. El relato enfatiza que la costa norte y central configuró el territorio base de la ocupación histórica de los pescadores y avala sus prerrogativas sobre el uso de ese espacio.

Hace cuarenta años, en ese paisaje, se inició una historia de desposesión. La primera modalidad de desalojo fue sutil e indirecta y se registró en la costa central, con la instalación de los clubes de pesca deportiva. Estas asociaciones cercaron los antiguos muelles, desarrollaron nuevas infraestructuras y limitaron las zonas para el amarrado de embarcaciones. Poco más tarde, en la costa norte, a los clubes existentes se sumaron las intervenciones urbanas desarrolladas en el marco de la última dictadura militar. Entre 1977 y 1978, viviendas de pescadores fueron demolidas. La reconquista de la costa implicó la desposesión violenta de los pescadores. A fines de los años setenta este espacio contaba con un valor estratégico: se localizaba cerca del estadio de Rosario Central, una de las subsedes del xi Campeonato Mundial de Fútbol, Argentina 1978. En los años sesenta se había pensado embellecer el Paseo Ribereño. La dictadura y el Mundial de 1978 generaron las condiciones de posibilidad para la puesta en marcha de esos proyectos urbanos tecnocráticos y autoritarios.

Ramón vincula esa primera modernización de la ribera norte, con la actual renovación de la costa central. En su evocación, el uso de la costa y el río como espacios públicos y recreativos aparece como la fuerza que organiza un ciclo de pérdida del territorio del pescador. Ese proceso culmina con la casi desaparición de los puntos de amarrado gratuitos para las canoas. Según Ramón, los clubes de pescadores fomentan guarderías que están pensadas para embarcaciones con finalidades recreativas y responden a las finanzas desahogadas de sus dueños. Actualmente, los clubes no ofrecen guarderías al alcance de los pescadores. Estos clubes fueron una de las primeras piezas de la privatización del espacio costero. Antes, la costa era un bien común, intervenido por las zonas portuarias, las cerealeras, los ferrocarriles y los clubes del norte. Actualmente, configura un espacio mixto público-privado que favorece la renta del mercado inmobiliario.

En Rosario el pescador cada vez tiene menos espacio, cada vez se le exigen más cosas. Las guarderías ya no las puede pagar un pescador [...]. De hecho a Rosario le hace falta espacio para el parque náutico que tiene, hay muchas embarcaciones y le falta lugar donde guardarlas. Por eso es el abuso y cobran precios irreales el alquiler [...]. (Ramón, entrevista personal, 7/06/2016)

El pescador tampoco es bienvenido en los clubes que fomentan la pesca deportiva. Por sus ritmos de trabajo y sus estilos de vida, los pescadores se transformaron en un elemento disruptivo en la vida social de los clubes de la ribera. Algunos duermen desde muy temprano, cuando todavía el sol está en el horizonte, se levantan durante la madrugada y antes del alba ya están en el agua tirando las redes. Otros salen al 
atardecer, arrojan sus redes en la noche y las recogen al amanecer. Cada uno tiene una explicación diferente para su ritmo, relacionada con el río, el itinerario de los cardúmenes, los hábitos de los peces y, también, aunque en menor medida, con sus preferencias. En cualquier caso, son ellos los que deciden las cadencias y las intensidades de su trabajo. No hay horario de entrada ni de salida, no hay labor regulada ni regulable (figura 2).

Los pescadores no pueden estar en los clubes, dan una mala imagen, andan con redes a cualquier hora de la noche, trabajan según su cultura y sus costumbres. No tiene patrón, no tiene horarios, no tienen que rendirle cuentas a nadie. Tan solo se relacionan con sus herramientas y el río. (Carlos, entrevista personal, 12/08/2016)

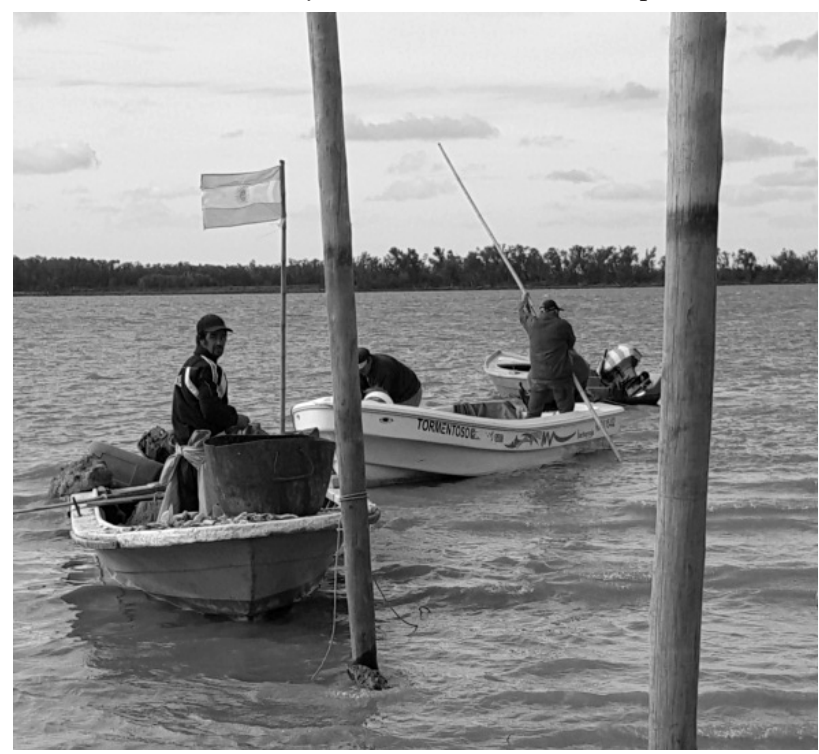

FIgURA 2 | Pesca artesanal en Rosario

FUENTE: ELABORACIÓN PROPIA

En las primeras apropiaciones de los clubes de pesca deportiva puede observarse una lógica doble. Por un lado, se registra una expropiación del espacio de amarrado y del lugar de residencia. Por otro y de modo complementario, se observa la desposesión de los medios y el estilo de vida de los pescadores artesanales. Esta tendencia se radicalizó con la remodelación de la costa en los ańos noventa. El proceso se abrió con el Parque de España, continuó con el Parque Scalabrini Ortiz y alcanzó su clímax en la renovación de la franja que va del Macro a Puerto Norte. Esa reconversión del espacio se recuesta sobre un waterfront capaz de producir una plusvalía inmobiliaria y recreativa tan amplia como específica (Scarpacci, 2014), y limita las condiciones de radicación de los pescadores en la costa central. La falta de un territorio estable y seguro supone una dificultad para la reproducción de la cultura de la pesca artesanal. La narrativa oficial de la recuperación de la costa como 
espacio público establece un diferendo profundo, casi insalvable, con el relato de desposesión que formulan los pescadores.

Hasta hace una década, buena cantidad de pescadores se afincaban en la barranca baja de la costa central. Esa ubicación establecía una relación para sí de plena visibilidad respecto al río que, al mismo tiempo, los tornaba invisibles para otros, el resto de la ciudad. Ramón habita en ese territorio oculto. Su permanencia es antes el resultado de una lucha jurídica que de un reconocimiento político del derecho a la territorialidad, a la ocupación de los terrenos y la preservación del universo simbólico asociado a la pesca. Hasta 2007, hubo sobre la barranca central un total de dieciocho viviendas. Una de las evidencias de esa batalla por la definición de los usos de la zona es que de ese emplazamiento, espacialmente disperso pero existencialmente coligado, subsisten solo cuatro casillas. La otra es que, al igual que el conflicto con los okupas, el proceso de desalojo estuvo marcado por el año de producción de Plan Urbano de Rosario (2007), en el que se hacía un balance y se diseñaban las perspectivas clave de la recuperación de la costa.

La inauguración del MACro configuró una nueva modalidad de aprovechamiento cultural de la costa (figura 3). El museo fue construido durante 2004, sobre la estructura de los Silos Davis de comienzos de la década de 1930. La conversión de este elevador de granos en museo sintoniza con las políticas patrimoniales del legado ferroportuario. Pese a su carácter público, el MACro y su bar buscan inscribirse en una familia de dispositivos museísticos, cuyos ejemplos argentinos son los edificios privados de exhibición artística Museo de Arte Contemporáneo de Buenos Aires (MAcba), Museo de Arte Latinoamericano de Buenos Aires (MAlba) y la Fundación Proa. MACRO intenta expresar unas formas artísticas de vanguardia urbana y unos registros minimalistas, vinculados con el diseño arquitectónico, las instalaciones y el arte conceptual (Kokosalakis, Bagnall, Selby, \& Burns, 2006; Plaza \& Haarich, 2009). Todas estas fórmulas están divorciadas de las actividades y las culturas de los pescadores de la ribera.

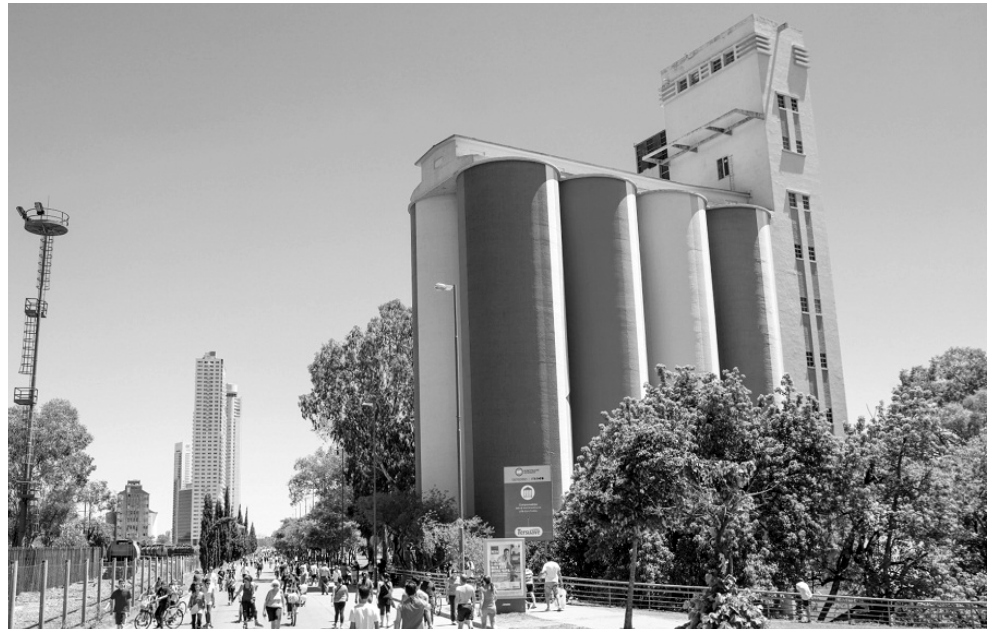

Figura 3 | Museo de Arte Contemporáneo Rosario (MACro)

FUENTE: ELABORACIÓN PROPIA 
Tras la inauguración del MACro, en febrero de 2005, el periódico La Capital publicó una nota sobre los pescadores de la zona. Su título esclarecía esta confrontación cultural y socioeconómica: "Viven colgados de la barranca, con techos de chapa y la vista más cara de Rosario". Uno de los tópicos centrales del texto era el de los contrastes suscitados entre las viviendas de los pescadores y la costa renovada, entre las fuerzas que organizaban una arquitectura simultáneamente patrimonial, minimalista y posmoderna y el rancherío caótico que orbitaba alrededor de fuerzas condenadas al destierro y la borradura.

Desde sus casas con techos de chapa gozan de la misma vista al río que los dueños de muchos departamentos de la zona tasados en miles de dólares el metro cuadrado [...] como nadie ven el puente Rosario Victoria y los espectáculos de fuegos artificiales $[\ldots]$ que el resto de los rosarinos descubre ahora que se hermoseó la costa. (La Capital, 6/02/2005)

La condición de posibilidad de esa convivencia diferencial era la invisibilidad de los ranchos (figura 4). Al promediar marzo de 2005, una porción de los muelles del Parque Espańa colapsó. Para prevenir accidentes, una orden judicial clausuró parte de la costa. Se efectuaron revisiones y estudios sobre las infraestructuras de soporte y el uso de la costa. El régimen de visibilidad de las comunidades pesqueras fue alterado y emergió un discurso sobre el riesgo que corría esa población. Una orden de desalojo afectó a las familias de pescadores (La Capital, 17/03/2005).

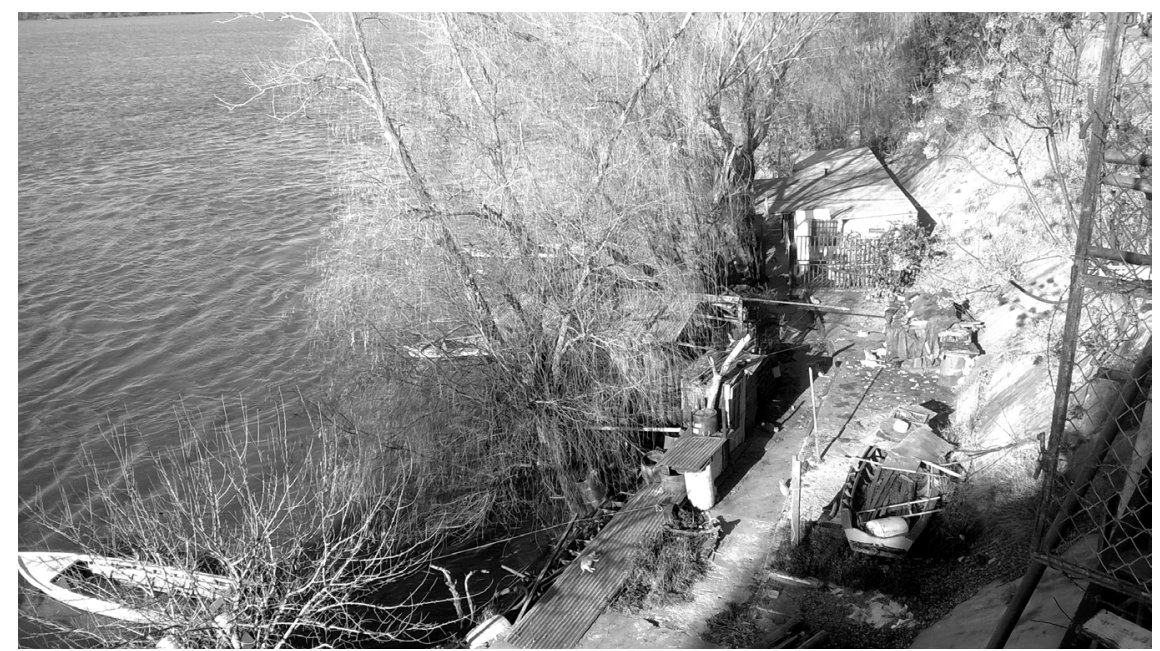

FIGURA 4 | Rancho de Ramón

FUENTE: ELABORACIÓN PROPIA

Frente a los embates, los pescadores reclamaron que se los trasladara respetando un radio próximo al río. Desplazarlos a una zona alejada implicaba dejarlos sin su principal sustento y la fuente que daba sentido a su cultura. Ante la inminencia de los traslados, intervino el Servicio Público de la Vivienda (sPv). La relocalización de 
la población se acordó sobre la base de subsidios eventuales. El dinero otorgado a las familias, según Ramón, apenas alcanzaba para comprar una casilla en algún asentamiento popular. Si bien hubo desalojos violentos y un acampe, las negociaciones avanzaron. La introducción del dinero por parte del SPV fracturó la resistencia y algunos ocupantes se trasladaron. Consecuentemente, el régimen de ocupación de las tierras varió ( $L a$ Capital 18/03/2005).

Dos años después, una casilla ubicada en Moreno y Wheelwright se desmoronó. Tres personas murieron (La Capital 30/03/2007). La inestabilidad de la barranca quedó asociaba al discurso sobre el riesgo. El 25 de septiembre de 2007, los empleados de Control Urbano llegaron acompañados por funcionarios de Defensa Civil, policías y bomberos. Una familia y varios residentes fueron "llevados arriba". Se constató el deteriorado estado de salud de un hombre portador de viH. Las órdenes de desalojo se efectivizaron. En los meses sucesivos, hubo otra serie de acampes y manifestaciones, abriéndose nuevas instancias de diálogo y negociación. Cuatro viviendas, sobre un total de casi veinte, volvieron a ser habitadas por pescadores. El resto fue demolido (La Capital 26/09/2007).

Cuando se produjeron los desalojos, hacía alrededor de diez años que la zona había comenzado a ser "recuperada" como espacio público. Inicialmente no hubo emprendimientos ni inversiones. El mantenimiento y las refacciones de la infraestructura eran rentables en el largo plazo, poco seductor para el mercado inmobiliario. La nivelación del terreno apenas alcanzó para que no se produjeran hondonadas e inundaciones. Ramón concibe el desmoronamiento de la barranca en continuidad con una historia de desidia pública sobre el territorio liminar formado por la ciudad, los ferrocarriles, el puerto, la barranca y el río.

La barranca no se toca desde que la hicieron los ingleses [...]. Se olvidaron de la barranca. Cuando se hicieron las placitas de arriba [lo que en el lenguaje del urbanismo se designa como "cadenas de espacios públicos"], los drenajes de los ingleses se obstruyeron, el agua comenzó a correr de otra manera, por donde pudo. Empezó a haber muchos barcos por el dragado del río y por la exportación de la soja. Los barcos levantan olas en el río que pegan en la barranca. Por un lado, hay lluvias más fuertes con malos drenajes: erosión por arriba. Del otro, hay muchos barcos grandotes que levantan olas: erosión por abajo. Más bien temprano que tarde la barranca se te derrumba en la cara si no haces nada. Y acá no se hizo nada. (Ramón)

Uno de los factores que precipitó la erosión de la barranca central fue la apertura de la costa. Ramón afirma que la "construcción de placitas" apunta a hermosear la ciudad, pero no intenta pensar a Rosario integralmente. Además, el informante considera que la restauración de los silos Davis y la implosión, en dos fases, de otro elevador de granos generaron vibraciones adicionales que desestabilizaron el frágil equilibrio de una barranca desatendida. Para Ramón se trata de un "llamado espacio público que es el lugar para la inversión de los privados [...]. Acá lo único verdaderamente público no es el espacio, sino el abandono y el fomento de los negocios" (Ramón).

La permanencia de Carlos y Ramón constituye una excepción. Su presencia depende de la militancia de ambos en la APDH y sus contactos con las abogadas de ese grupo, quienes los asesoraron ante las intimaciones judiciales. Las familias 
restantes fueron desalojadas y quince viviendas, demolidas. A los que se fueron les dieron compensaciones monetarias. Para los que se quedaron, la zona se volvió más inhóspita. La batalla por la posesión del terreno describe un camino sinuoso. Aunque Ramón y Carlos lograron quedarse, amparados por capitales relacionales, políticos y jurídicos, la evaluación que hacen de su presencia en la ribera no es ingenua ni optimista. Además, saben que su cultura de pescadores artesanales está muy lejos de ser un elemento reconocido por las autoridades.

...fue una batalla ganada a medias. Ganada, porque podemos tener este espacio; y perdida, porque mis hijos que se criaron acá ya no van a tener hijos que se críen en un lugar así. Esto es lo último que queda. En veinte años, si no antes, van a intentar corrernos. Vamos a resistir. (Ramón)

La historia de los pescadores es circular. Su narración de vida en la ribera vuelve sin cesar al punto de partida: "nos estamos quedando sin espacio, estamos perdiendo territorio". Esto, en parte, es consecuencia de las fuerzas y los intereses que reinventan el río; y, en parte, obedece a cierta desorganización de los pescadores como grupo social y actor político. Pero esa pérdida del territorio, esa desterritorialización a la que es sometida la vida de los pescadores, también constituye una sustracción de su experiencia e identidad. El proceso de acumulación por desposesión no solo erosiona el territorio y declina algunas actividades económicas, sino que también interviene en una desarticulación de las subjetividades que, con sus prácticas, dieron sentido al mundo de la ribera y de la ciudad ferroportuaria.

La planificación urbana observa a los pescadores artesanales como personajes pintorescos, parte de un pasado condenado a la desaparición en pos del desarrollo de una ciudad de diseńo con una interfaz de espacios públicos y paisajes que la integre al río. Sin embargo, los pescadores son el producto de una forma de vida que se configura en el paciente aprendizaje de las técnicas de pesca, de las lógicas de reproducción, localización y diversidad de las especies, efectuado en el marco de una multiplicidad habitada por la historia, la tradición oral y el sentido práctico. Expresan una manera de relacionarse con el trabajo y el ambiente a partir de la subsistencia, la comercialización primaria y las tecnologías artesanales. La subjetividad de estos pescadores pone entre paréntesis las fórmulas socioeconómicas hegemónicas, cuestionando la relación salarial y la dependencia patronal como únicas modalidades de la reproducción social. Además, discuten la presunta unanimidad de la valoración favorable de la recuperación de la costa como espacio público y derecho ciudadano. Este tipo de experiencias y culturas son las que la nueva gubernamentalidad, a través de sus órdenes de desalojo, propuestas de relocalización y planes de rehabilitación de la costa, parece apenas comprender.

\section{Conclusiones}

Los okupas fueron un emergente de una cultura originada en una incipiente globalización periférica y la infraestructura remanente de una ciudad posferroportuaria. Fueron los introductores de las artes urbanas y sus prácticas culturales constituyeron una ruptura en la trama de la cultura local. Si bien en el centro de su trabajo 
estaba la corporalidad, el producto de esa labor era inmaterial, formaban parte de movimientos culturales semejantes diseminados a escala global y su localización resultaba más eventual que histórica. Los pescadores estaban dedicados a actividades de extracción artesanal de larga correlación histórica con la ribera, con un poderoso enlace entre el ambiente y el territorio. El despliegue temporal, la extensión espacial, las formas de habitar y la relación ambiente-territorio-trabajo eran diferentes. La propuesta de los okupas se aproximaba a las ideas de reapropiación de las ruinas ferroportuarias, su cultura era muy dinámica y una hija disidente de la globalización. Mientras, los pescadores se presentan como los efectos de una historia prolongada y una cultura específica.

En este marco, resulta paradójico que los okupas fueran desalojados para habilitar un centro de danza tradicional, como la Casa del Tango; y los pescadores, en pos del establecimiento de un Museo de Arte Contemporáneo. Los okupas y los pescadores eran sujetos residuales de la transformación, y su desterritorialización también comportaba una desposesión subjetiva. Se trataba de un avance sobre los modos de subjetivación respectivamente experimentales y tradicionales de las comunidades artísticas y pesqueras afincadas en la costa central. Ambas comunidades compartían cierto individualismo en sus modalidades de producción y reproducción, y contienen una multiplicidad. Poseen un modo de producción artesanal, construyen lazos complejos con una ciudad de la que dependen relativamente. Queda evidenciado que esa dependencia distanciada se produce más en el nivel del intercambio que en el de la producción y reproducción comunal. La territorialización de ambos grupos arraiga en un margen urbano; ambos priorizan la libertad y lo alternativo y se localizan en una zona abandonada de la costa central. La construcción narrativa de la identidad comunal se basa en el antagonismo, a partir de la producción de una diferencia vital frente a las lógicas hegemónicas del mercado y las categorías de segregación-exclusión (desalojos y relocalización) y colonización-inclusión (integración a la Escuela Municipal de Artes Urbanas y subsidios eventuales) con que la gubernamentalidad local los clasifica e intervine.

Tanto para okupas como para pescadores, las luchas intentan amortiguar una desposesión territorial específica, y denunciar el declive de la diversidad de usos y apropiaciones de la costa. Polemizan con la instalación de dos dispositivos arquitectónicos patrimoniales y culturales con diversos niveles de extraterritorialidad respecto a la cultura local, que se inauguran casi simultáneamente: uno enlazado a los barrios rehabilitados a partir del impacto global del tango (Carman, 2006) en Buenos Aires (La Casa del Tango) y el otro a los artefactos museísticos abstractos de las ciudades globales (MACro). Pero, también, ponen en cuestión el ejercicio del derecho a la ciudad a través de la construcción de espacios públicos como derivación de los convenios público-privados. Las territorializaciones y las prácticas artístico-productivas de estos sujetos problematizan la gubernamentalidad basada en la simple convergencia u oposición binaria Estado/Mercado y Público/Privado. De forma práctica propusieron formas comunitarias de producción del territorio y la cultura urbana.

Los planes estratégicos fueron incapaces de procesar el desafío y las problematizaciones que le interpusieron dos culturas alternativas. Con grados de sutileza y 
dilación crecientes, la resolución de los conflictos fue asumida por el Poder Judicial. En el caso de los okupas, tras las primeras intervenciones informales, el despliegue de fuerzas fue exagerado. El desalojo de los pescadores y la demolición de la mayor parte de sus viviendas, compensada a través de subsidios ocasionales, empleó una violencia indirecta que se amparó en la idea del riesgo y la vulnerabilidad de esa población. Los resultados de esa intervención fueron algo menos definitivos de aquellos alcanzados por la Gendarmería Nacional en el Galpón.

Con todo, ambas operatorias destacan las dificultades de la nueva gubernamentalidad local para trabajar con lo que queda por fuera de su horizonte de legibilidad (Scott, 1998). Los sujetos residuales de la rehabilitación de la costa fueron apartados de su gran trasformación. Fragmentariamente, algunos fueron incluidos por los nuevos dispositivos institucionales, como la EMAU. No obstante, estos sujetos estuvieron lejos de convertirse en una de las fuerzas impulsoras de una política urbana capaz de transformar y construir no solo espacios públicos y edificios, sino también las condiciones políticas para la emergencia de una cultura urbana basada en la multiplicidad, la diferencia y lo común (Laval \& Dardot, 2016).

\section{Referencias bibliográficas}

Adell, R. \& Martínez, M. (coords.) (2004). ¿Dónde están las llaves? El movimiento okupa: prácticas y contextos sociales. Madrid: Libros de la Catarata.

Arantes, O., Vainer, C., \& Maricato, E. (2000). A cidade do pensamento único. Desmanchando consensos. Petrópolis: Editora Vozes.

Barenboim, C. \& Tomino, G. (2016). Estrategias de comercialización y marketing urbano: el producto Puerto Norte Rosario, Argentina. Collectivus, Revista de Ciencias Sociales, 3(1), 66-90. http://investigaciones.uniatlantico.edu.co/revistas/index.php/ Collectivus/article/view/1479/1333

Borja, J. \& Castells, M. (1997). Local y global. La gestión de las ciudades en la era de la información. Madrid: Taurus.

Caparros, M. (2006). Amor y anarquía. La vida urgente de María Soledad Rosas. Buenos Aires: Planeta.

Carman, M. (2006). Las trampas de la cultura. Los intrusos y los nuevos usos del barrio de Gardel. Buenos Aires: Paidós.

Castillo, T. I., Baigún, C. R. M., \& Minotti, P. G. (2016). Assessment of a fisheries legal framework for potential development of an ecosystem approach to fisheries management in large rivers. Fisheries Management and Ecology; 23(6), 510-518. http:// dx.doi.org/10.1111/fme.12192

Cuenya, B. (2012). Movilización de plusvalías en un gran proyecto urbano. El caso de Puerto Norte, Rosario. En B. Cuenya, P. Novais, \& C. Vainer (comps.), Grandes proyectos urbanos. Miradas criticas sobre la experiencia argentina y brasileña (pp. 67-118). Buenos Aires: Café de las Ciudades.

Foucault, M. (2006). Seguridad, territorio y población. Curso del Collège de France: 1977-1978. Buenos Aires: Fondo de Cultura Económica. 
Foucault, M. (2009). La gubernamentalidad. En G. Giorgi \& F. Rodríguez (comps.), Ensayos sobre biopolitica. Excesos de vida (pp. 41-57). Buenos Aires: Paidós.

Foucault, M. (2010). El cuerpo utópico. Las heterotopias. Buenos Aires: Nueva Visión.

Galimberti, C. (2016). Políticas públicas en el desarrollo de grandes proyectos de reconversión urbana. Caso Puerto Norte en Rosario, Argentina. Caderno metrópole, 18(36), 559581. https://revistas.pucsp.br/metropole/article/view/2236-9996.2016-3613

Hackworth, J. (2007). The neoliberal city. Governance, ideology, and development in American urbanism. Ithaca, NY y Londres: Cornell University Press.

Harvey, D. (1990). La condición de la posmodernidad. Buenos Aires: Amorrortu.

Harvey, D. (2005). A produçâo capitalista do espaço. São Paulo: Anneblume.

Jajamovich, G. (2012). De parque España a Puerto Madero. Proyectos urbanos y gestión entre Argentina y España. En B. Cuenya, P. Novais, \& C. Vainer, (comps.), Grandes proyectos urbanos. Miradas criticas sobre la experiencia argentina y brasileña (pp. 7-25). Buenos Aires: Café de las ciudades.

Janoschka, M. (2002). El nuevo modelo de ciudad latinoamericana: fragmentación y privatización. EURE. Revista Latinoamericana de Estudios Urbano Regionales, 28(85), 11-29. https://www.eure.cl/index.php/eure/article/view/1239

Janoschka, M. (2016). Gentrificación, desplazamiento, desposesión: procesos urbanos claves en América Latina. Revista INVI, 31(88), 27-71. http://revistainvi.uchile.cl/index.php/ INVI/article/view/1087

Kokosalakis, C., Bagnall, G., Selby, M., \& Burns, S. (2006). Place image and urban regeneration in Liverpool. International Journal of Consumer Studies, 4(30), 389-397. https:// pureportal.coventry.ac.uk/en/publications/place-image-and-urban-regeneration-inliverpool

Kozak, D. \& Feld, N. (2018). Grandes proyectos urbanos y su relación con la ciudad: el caso de Puerto Norte (Rosario, Argentina). EURE, 44(133), 187-210. http://www.eure.cl/ index.php/eure/article/view/2244/1115

Laval, C. \& Dardot, P. (2016). Común. Ensayo sobre la revolución del siglo XXI. Barcelona: Gedisa.

Levin, M. (2012). Los grandes proyectos urbanos. La experiencia de la ciudad de Rosario (Argentina). Café de las Ciudades, 11(119). http://www.cafedelasciudades.com.ar/ planes_119.htm

Madoery, O. \& Caminotti, M. (2000). El Plan Estratégico Rosario: logros, dificultades y desafíos. En Informe sobre Desarrollo Humano en la Provincia de Buenos Aires 2000 (pp. 99-102). Buenos Aires: Honorable Senado de la Nación - Banco de la Provincia de Buenos Aires.

Martínez López, M. (2012). The squatter's movement in Europe: A durable struggle for social autonomy in urban politics. Antipode, 4(45), 1-22.

Peck, J. (2015). A vueltas de la ciudad creativa. En Observatorio Metropolitano de Madrid. El mercado contra la ciudad. Sobre globalización, gentrificación y politicas urbanas (pp. 53106) Madrid: Traficantes de Sueños.

Plaza, B. \& Haarich, S. (2009). Museums for urban regeneration? Exploring conditions for their effectiveness. Journal of Urban Regeneration and Renewall, 3(2), 259-271. http:// www.scholars-on-bilbao.info/fichas/Plaza_Haarich_JURR_2009.pdf

Portes, A., Roberts, B., \& Grimson, A. (eds.) (2005). Ciudades latinoamericanas. Un análisis comparativo en el umbral del nuevo siglo. Buenos Aires: Prometeo. 
Robles, G. (2015). El complejo cultural Parque de España (Rosario 1977-1992). Folia histórica del nordeste, 22, 259-283. http://revistas.unne.edu.ar/index.php/fhn/article/view/59

Scarpacci, M. (2014). El GPU de Puerto Norte en el Planeamiento Estratégico Socialista: Rosario, Argentina 2003-2013. Tesis. MA Dissertation in Urban Studies, Flacso-Ecuador, Quito.

Scott, J. (1998). Seeing like state: How searching schemes to improve the human condition have failed. New Heaven, ст: Yale University Press.

Vera, P. (2017). Procesos de recualificación urbana e imaginarios de la innovación. El caso de Rosario, Argentina. EURE, 43(129), 209-234. http://www.eure.cl/index.php/eure/ article/view/1582/994

\section{Entrevistas}

Carlos, pescador artesanal. Rosario, 12/08/2016.

Griego, malabarista, acróbata y payaso callejero. Docente de la Escuela Municipal de Artes Urbanas (EMAU). Rosario, 26/03/2014.

Pablo y Amalia (entrevista conjunta), Red de Solidaridad con Chiapas, talleristas del Galpón Okupa. Rosario, 4/06/2015.

Ramón, pescador artesanal. Rosario, 70/6/2016.

Tati, malabarista y payaso callejero. Actualmente director del estudio Garage 29 (Bruselas). Rosario, 18/12/2014.

Xaxi, participante del Galpón Okupa, creador de Nómade Comunicación. Rosario, 28/05/2015.

Zalo, organizador de recitales, actual docente de escuela media. Entrevista, Rosario, 20/05/2015.

\section{Periódicos}

Clarin, 30/08/1998, Buenos Aires.

El Ciudadano, 9/10/1998, 30/10/1998, Rosario.

La Capital, 13/08/1998, 18/03/2005, 30/03/2007, 26/09/2007, Rosario.

Página 12, 12/12/1998, Buenos Aires.

Rolling Stone (1998). Año 1, Número 5, Buenos Aires.

\section{Documentos de planificación}

Della Paolera, C., Guido, Á., \& Farengo, A. (1935). Plan Regulador y de Extensión de Rosario. Rosario: Municipalidad de Rosario.

Montes, A. (1964). Plan Rosario. Ley Nacional 16052 y sus antecedentes. Rosario: Centro de Estudios Nacionales, Provinciales y Municipales.

Municipalidad de Rosario (1967). El Plan Regulador Rosario. Rosario: s/e.

Municipalidad de Rosario (1991) Actualización del Plan Regulador y Bases Documentales para la revisión del Código Urbano. 2 vols. Rosario: Secretaría de Planeamiento.

Municipalidad de Rosario (1998). Plan Estratégico Rosario 1998. Rosario: Municipalidad de Rosario.

Municipalidad de Rosario (1999). Nuevo Plan Director, Bases para el Acuerdo. Rosario: Secretaría de Planeamiento.

Municipalidad de Rosario (2011). Plan Urbano Rosario 2007-2017. Rosario: Municipalidad de Rosario. 